\title{
Combination stress analysis of immediate implant provisional restoration using cyclic fatigue test and three-dimensional finite element analysis (3D FEA)
}

Kikue Yamaguchi, Sawako Yokoyama, Yuichi Ishiura, Yasuhiro Hotta, Takashi Miyazaki, Kazuyoshi Baba, Masahiko Ozeki

Showa University, Tokyo, Japan

\section{Background and Aim}

In recent years, immediate loading implant treatment has been widely recognized as an effective solution for edentulous patients Risk factors of disintegration associated with immediate loading include excessive occlusal force such as bruxism, and relating to the technical complication, the fracture of temporary restoration has been pointed out. The fracture of temporary restoration can be considered to increase the micro movement around implant, and lead to fail osseointegration. A large numbers of stress analysis for implant prosthesis has been reported by 3D FEA and mechanical tests, but it has not been clarified the cause of fracture of the temporary restoration in multidimensional analysis. In this study, we analyzed the stress concentration in patient models by 3D FEA and the cyclic fatigue test in materials for temporary restoration, and tried out the combination stress analysis.

\section{Methods and Materials}

I. $10^{5}$ cyclic fatigue test

material : $25 \mathrm{~mm}$ in length $\times 10 \mathrm{~mm}$ in width $\times 2 \mathrm{~mm}$ in thickness the specimens are for CAD/CAM (Aadva PMMA disc, GC Co.).

three-point bending test

i) Real experiment (Fig.1)

ii) Reproducing experiment (Fig.2)

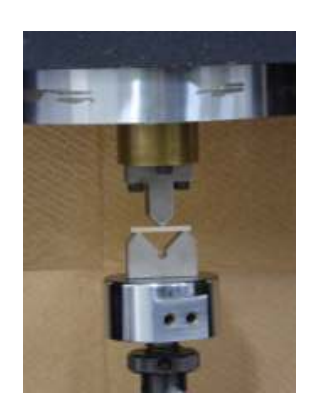

Fig. 1 : three-point bending test (AG-Xplus, SHIMADZU, Kyoto)

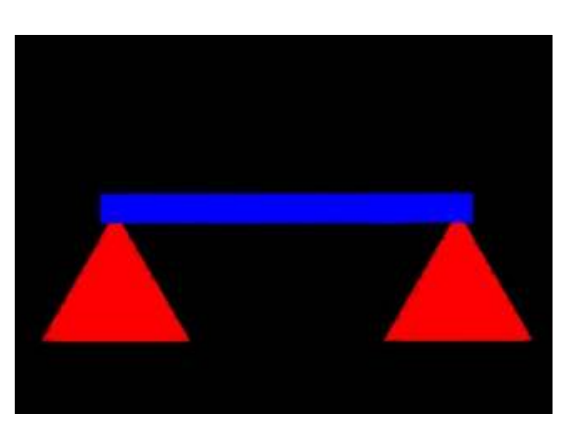

Fig. 2 : FEA model (Mechanical Finder ver.7.0, Research Center of Computational Mwchanics, Tokyo)
III. Patient models

To recognize the clinical situation, another FEA was done with the immediate load patient models. These models were maxillary edentulous patients before implant placement (Fig.3). To assume immediate load, the interface between the bone and the implant was set as a "contact state" (frictional coefficient $=0.33$ ). The physical property values of the bone were calculated from the CT values and set for each element, and the physical property values of other elements were set based on the known values (table 1). The load condition was set based on the occlusal force data recorded from a patient with bruxism, and the constraint condition was set as the maxillary sinus upper margin (Fig. 4).

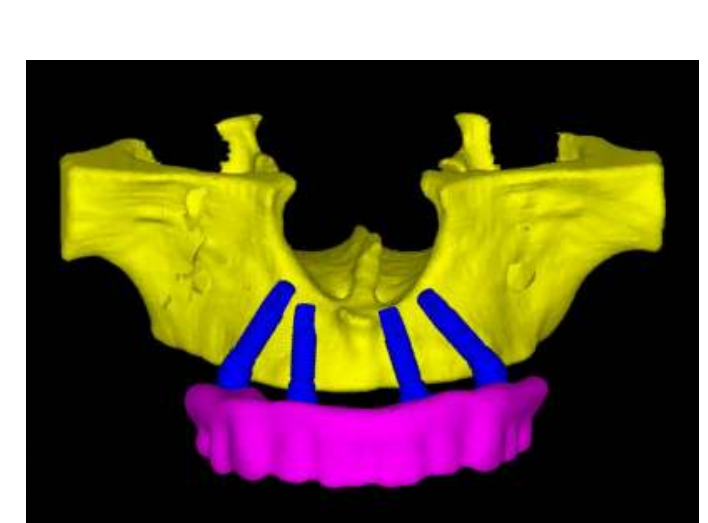

Fig. 3 : FEA model of immediate loading
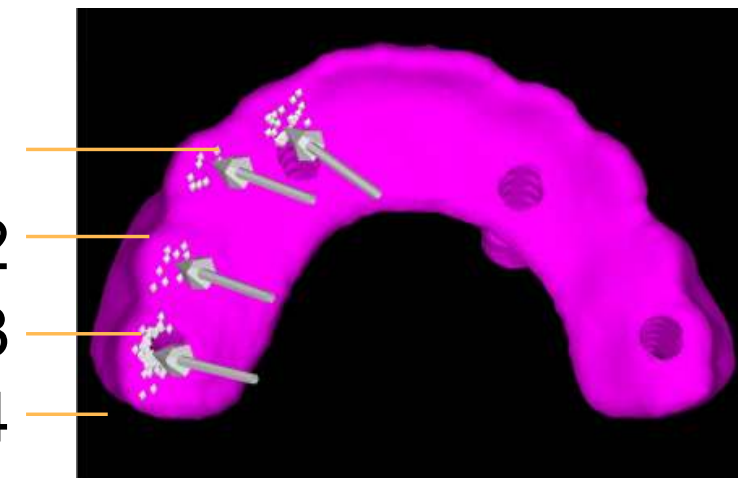

Fig. 4 : loading condition $1: 42.4 \mathrm{~N}, 2: 45.4 \mathrm{~N}, 3: 62.5 \mathrm{~N}, 4: 273.2 \mathrm{~N}$ ( occlusal view )

Table 1 : material properties used in this study

\begin{tabular}{c|c|c|c|} 
part & maxillary bone & $\begin{array}{c}\text { implant } \\
\text { complex }\end{array}$ & $\begin{array}{c}\text { temporary } \\
\text { restoration }\end{array}$ \\
\hline $\begin{array}{c}\text { young's } \\
\text { modulus } \\
(\mathrm{GPa})\end{array}$ & $\begin{array}{c}\text { calculate from } \\
\mathrm{HU}\end{array}$ & 106 & 0.38 \\
\hline poisson's ratio & 0.4 & 0.19 & 0.4 \\
\hline
\end{tabular}
patient under

\section{Results}

I. $10^{5}$ cyclic fatigue test

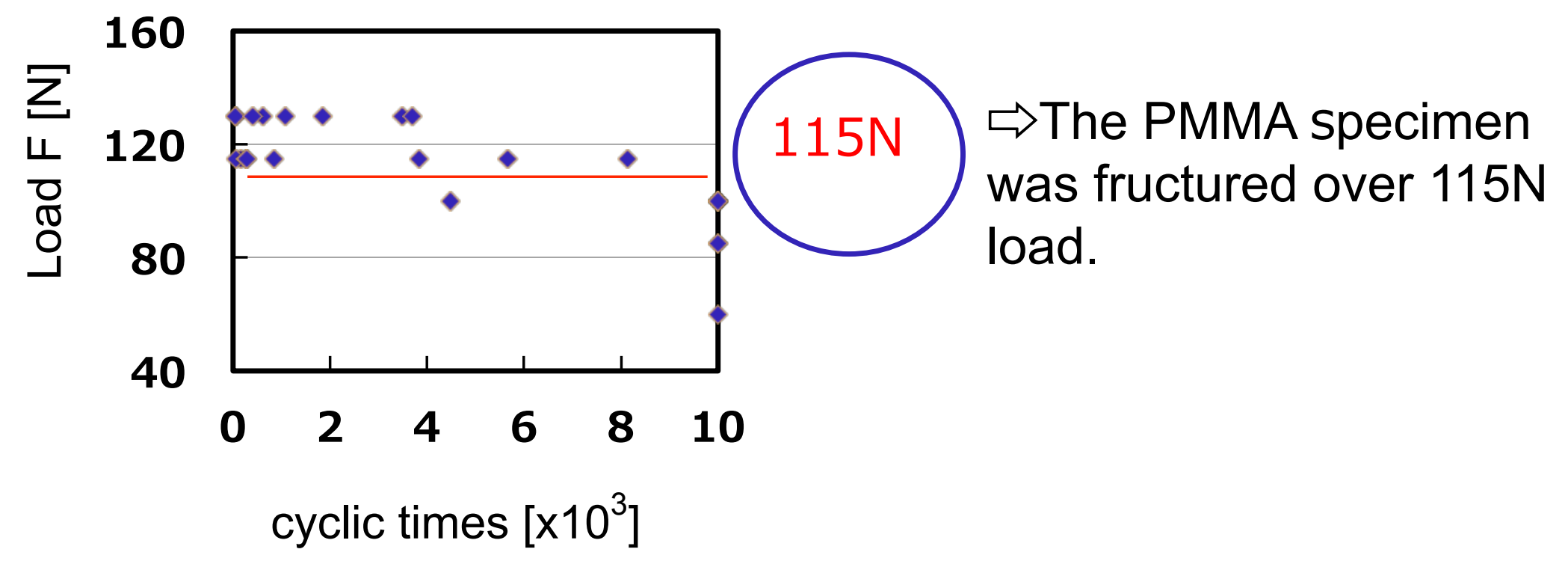

II. three-point bending test

i) Real experiment

ii) Reproducing experiment

\begin{tabular}{cc} 
(1) & 79.58379 \\
(2) & 84.635 \\
(3) & 77.41407 \\
(4) & 77.38014 \\
(5) & 82.48886 \\
ave. & 80.30037 \\
\hline
\end{tabular}

Fig. 5 : maximum the maximum tensile stress at $115 \mathrm{~N}$

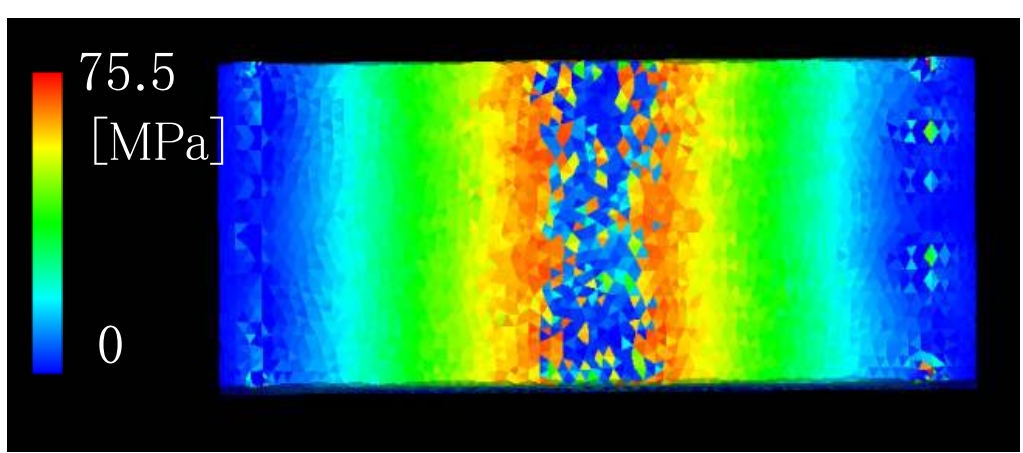

Fig. 6 : contour map of the

$\Rightarrow$ Maximum value of maximum tensile stress was $75.5 \mathrm{MPa}$ with FEA. maximum tensile stress at $115 \mathrm{~N}$

Real experiment and reproducing experiment with FEA was almost same result.

III. Patient models
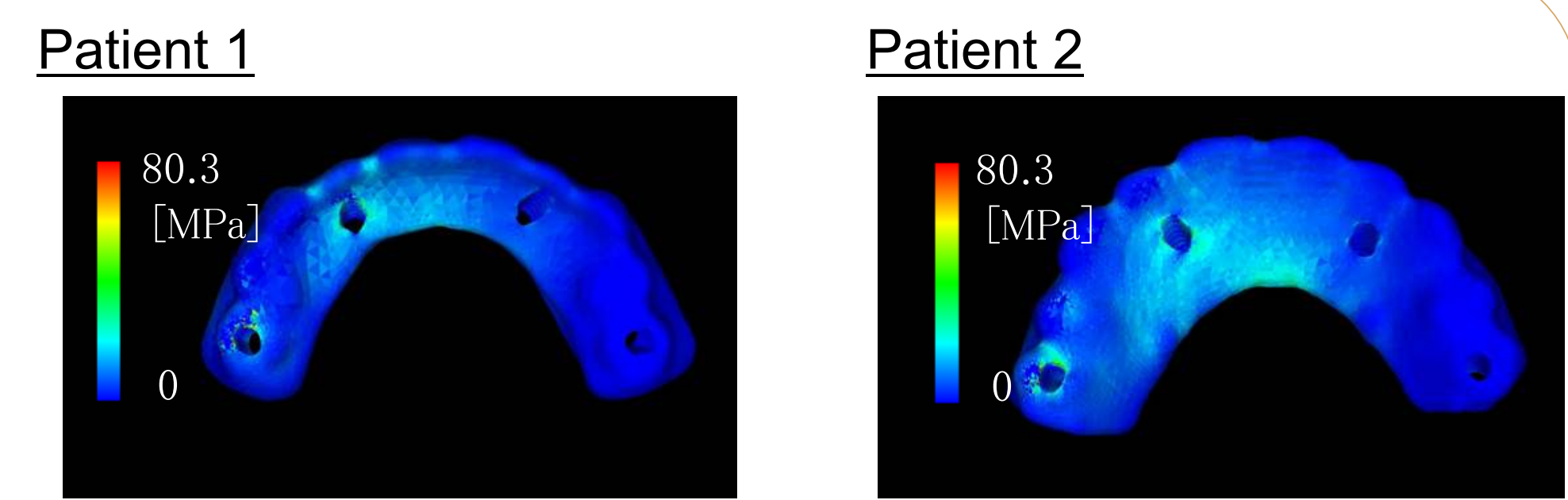

Patient 3

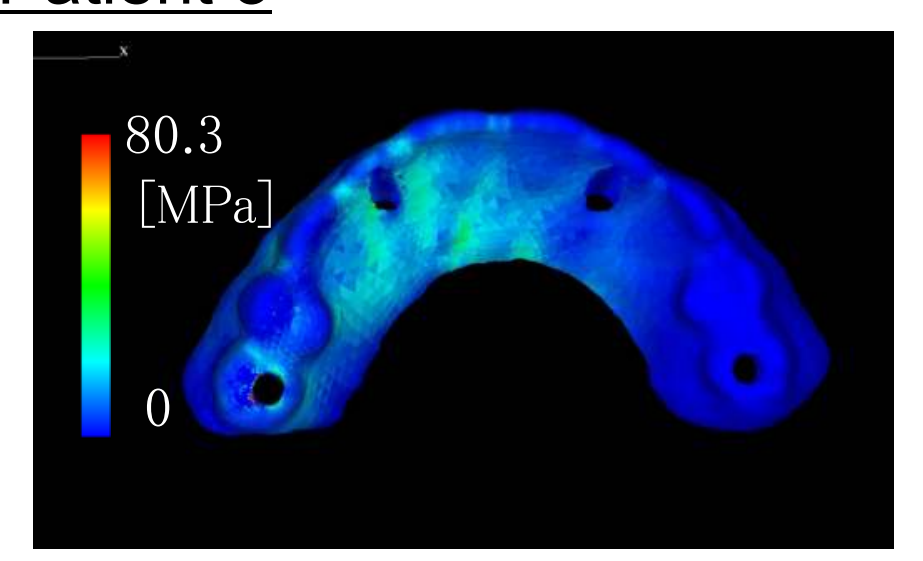

Fig. 8 : contour maps of

Maximum tensile stress

In the FEA patient models, the maximum tensile stress over 75.5 MPa was found at the PMMA material around temporary cylinder, and maximum value were 247.7 MPa, 258.8 MPa and 290.8MPa for each patient.

\section{Conclusions}

The fracture of temporary restoration in immediate loading treatment is estimated to occur around temporary cylinders. It is necessary to consider temporary restoration designs or reinforcement not to exceed the maximum tensile stress in real clinical situation. From the results of this study, it is suggested that the effective possibility of combination stress analysis in real material and FEA model. 